\section{OP0271 JUVENILE LOCALIZED SCLERODERMA: A LARGE RETROSPECTIVE COHORT STUDY FROM A TERTIARY CARE CENTER}

B. Egeli ${ }^{1}$, J. Dallas ${ }^{1}$, E. Anderson ${ }^{1}$, M. Min ${ }^{2}$, D. Mazori², S. Gellis ${ }^{2}$, M.

B. Son ${ }^{1}$, R. Sundel ${ }^{1}$, R. Vleugels ${ }^{2}$, F. Dedeoglu' ${ }^{1}$ Boston Children's Hospital, Rheumatology, Boston, United States of America; ${ }^{2}$ Boston Children's Hospital, Dermatology, Boston, United States of America

Background: Juvenile Localized Scleroderma (jLS) is a rare pediatric inflammatory disease of skin and underlying tissues that may cause significant functional impairment and disfigurement. Management approaches vary and an optimum treatment regimen is lacking. In 2012, a group of jLS researchers of Childhood Arthritis and Rheumatology Research Alliance (CARRA) proposed consensus treatment plans (CTPS), aimed to streamline the approach to care for jLS patients.

Objectives: This study aimed to evaluate a large jLS patient cohort seen over a 21-year period in a single tertiary care pediatric hospital in the USA, in order to examine treatments utilized and determine parameters for systemic therapy initiation.

Methods: This retrospective cohort study included jLS patients with disease onset in childhood ( $\leq 18$-years of age) who were seen in rheumatology, dermatology, or combined rheumatology-dermatology clinics from 1999-2020, with $\leq$ 3 years of follow-up. Data on demographics, disease characteristics, therapies prescribed, and treatment trends were analyzed.

Results: Of the $270 \mathrm{jLS}$ patients identified, 101 fulfilled the inclusion criteria. The primary reason for exclusion was $<3$ years of follow-up. Selected demographic data and disease characteristics of patients are shown in Table 1. There were no statistically significant differences in most patient and disease characteristics between patients who received systemic treatment and those who did not. There were no significant differences in baseline laboratory values. The group treated with systemic therapy did have higher rates of extracutaneous involvement and had a higher proportion of patients with a generalized morphea phenotype.

Table 1. Demographic and Disease Characteristics

\begin{tabular}{lcccc}
\hline & $\begin{array}{c}\text { All Patients } \\
(\mathrm{n}=101)\end{array}$ & $\begin{array}{c}\text { On Systemic } \\
\text { Therapy } \\
(\mathrm{n}=63)\end{array}$ & $\begin{array}{c}\text { No Systemic } \\
\text { Therapy } \\
(\mathrm{n}=38)\end{array}$ & p value \\
\hline Age-onset (Y), median (IQR) & $7.5(6.4)$ & $9(6)$ & $7(4)$ & NS \\
Age-diagnosis(Y), median (IQR) & $9(7.9)$ & $10(6.7)$ & $9(3.7)$ & NS \\
Diagnostic delay(M), median (IQR) & $10(2.9)$ & $12(13)$ & $7.5(17)$ & NS \\
Follow-up (M), median (IQR) & $74(69.3)$ & $65(44.5)$ & $78(47.7)$ & NS \\
Subtype & 56 & 39 & 17 & NS \\
Linear & 29 & 20 & 9 & NS \\
Face & 23 & 4 & 19 & $<0.0001$ \\
$\quad$ Circumscribed & 2 & 2 & 0 & NS \\
$\quad$ Mixed & 20 & 18 & 2 & 0.004 \\
$\quad$ Generalized & 19 & 18 & 1 & 0.001 \\
Extracutaneous Involvement & & & & \\
Clinic type & 29 & 2 & 27 & $<0.0001$ \\
$\quad$ Dermatology & 21 & 19 & 2 & 0.003 \\
$\quad$ Rheumatology & 51 & 42 & 9 & $<0.0001$ \\
$\quad$ Combined & & & & \\
\hline
\end{tabular}

The majority of patients who were on systemic immunomodulatory therapy were treated with methotrexate $(59 / 63,93.6 \%)$ and/or systemic corticosteroids $(21 / 63$, $33 \%) .5$ patients were treated with hydroxychloroquine, 2 of which were also on methotrexate. 6 patients on methotrexate were either switched to or had mycophenolate mofetil added as concomitant therapy. The most common adverse effects observed in methotrexate-treated patients were gastrointestinal complaints $(12 / 61,19.7 \%)$ and fatigue $(7 / 61,11.5 \%)$. The median treatment duration was 50 months (IQR: 33.5). Patients were more likely to receive systemic therapy if they were followed in rheumatology or combined rheumatology-dermatology clinics as compared to dermatology clinics. Finally, $78 \%$ of patients with jLS received systemic treatment after 2013 (a year after publication of the CARRA jLS CTP) as compared to $55 \%$ of patients prior to $2013(p<0.05)$.

Conclusion: This jLS cohort is one of the largest reported from a single center and reflects an increase in the use of systemic therapy since publication of CARRA CTPs in 2012. Further studies on long-term treatment outcomes and therapeutic approaches utilized when first-line treatment failures occur are warranted

\section{REFERENCES:}

[1] Li SC, Torok KS, Pope E, et al. Development of consensus treatment plans for juvenile localized scleroderma: a roadmap toward comparative effectiveness studies in juvenile localized scleroderma. Arthritis Care Res (Hoboken). 2012;64(8):1175-1185.

Disclosure of Interests: Bugra Egeli: None declared, Johnathan Dallas: None declared, Edwin Anderson: None declared, Michelle Min: None declared, Daniel
Mazori: None declared, Stephen Gellis: None declared, Mary Beth Son: None declared, Robert Sundel: None declared, Ruth Vleugels: None declared, Fatma Dedeoglu Consultant of: Novartis

DOI: 10.1136/annrheumdis-2021-eular.4066

\begin{tabular}{|l|l}
\hline OP0272 & 68GA-FAPI-04 PET/CT STUDY EXTENSION FOR \\
THE ASSESSMENT OF FIBROBLAST ACTIVATION \\
AND RISK EVALUATION IN SYSTEMIC SCLEROSIS- \\
RELATED INTERSTITIAL LUNG DISEASE
\end{tabular}

C. Bergmann ${ }^{1}$, J. H. W. Distler ${ }^{1}$, C. Treutlein ${ }^{2}$, K. Tascilar ${ }^{1}$, A. T. Mueller ${ }^{1}$ A. Atzinger ${ }^{3}$, A. E. Matei ${ }^{1}$, J. Knitza ${ }^{1}$, A. H. Györfi' ${ }^{1}$ A. Lueck ${ }^{1}$, C. Dees ${ }^{1}$, A. Soare ${ }^{1}$, A. Ramming ${ }^{1}$, V. Schönau', O. Distler ${ }^{4}$, O. Prante ${ }^{3}$, P. Ritt ${ }^{3}$, T. I. Goetz ${ }^{3}$, M. Koehner ${ }^{3}$, M. Cordes ${ }^{3}$, T. Baeuerle ${ }^{2}$, T. Kuwert ${ }^{3}$, G. Schett ${ }^{1}$ C. Schmidkonz ${ }^{3} .{ }^{1}$ University Hospital Erlangen, Department Internal Medicine 3, Erlangen, Germany; ${ }^{2}$ University Hospital Erlangen, Department Radiology, Erlangen, Germany; ${ }^{3}$ University Hospital Erlangen, Department Nuclear Medicine, Erlangen, Germany; ${ }^{4}$ University Hospital Zuerich, Department Rheumatology, Zuerich, Switzerland

Background: Interstitial lung disease (ILD) is the most common cause of death in systemic sclerosis (SSc). To date, the progression of SSc-ILD is judged by the accrual of lung damage on computed tomography (CT) and functional decline (forced vital capacity). However, this approach does not directly assess the activity of tissue remodeling. Moreover, prediction of the course of ILD in individual SSc patients remains challenging. Fibroblast Activation Protein (FAP) is a specific, ex vivo validated marker for activated fibroblasts

Objectives: The aims of this study were: 1. To assess differences in the uptake of ${ }^{68} \mathrm{GA}-\mathrm{FAPI} 04$ in SSc-ILD patients compared to controls, to analyze 2 . whether ${ }^{68} \mathrm{GA}-\mathrm{FAPI} 04$ uptake at baseline correlates with other risk factors of disease progression and 3 . Whether ${ }^{68} \mathrm{GA}-\mathrm{FAPI} 04$ uptake is associated with the course of SSc-ILD.

Methods: Between September 2018 and April 2020, 21 patients with SSc-ILD confirmed by HRCT and onset of SSC-ILD within $\leq 5$ years or signs of progressive ILD and 21 controls without ILD were consecutively enrolled. All participants underwent ${ }^{68} \mathrm{Ga}-\mathrm{FAPI}-04 \mathrm{PET} / \mathrm{CT}$ imaging and standard-of-care procedures including HRCT and lung function testing (PFT) at baseline. Patients with SScILD patients were followed-up for 6 months with HRCT and PFT. Follow-up ${ }^{68} \mathrm{Ga}-\mathrm{FAPI}-04 \mathrm{PET} / \mathrm{CT}$ scans were obtained in a subset of patients treated with nintedanib. We compared baseline ${ }^{68} \mathrm{Ga}-\mathrm{FAPI}-04$ PET/CT uptake to standard diagnostic tools and currently used predictors of ILD progression. The association of ${ }^{68} \mathrm{Ga}$-FAPI-04 uptake with changes in FVC was analyzed using mixed-effects models.

Results: ${ }^{68} \mathrm{Ga}-\mathrm{FAPI}-04$ accumulated in fibrotic areas of the lungs in SSc-ILD compared to controls with a median (q1-q3 interval) wISUVmean of 0.8 (0.6 to $2.1)$ in the SSc-ILD group and $0.5(0.4$ to 0.5$)$ in the control group $(p<0.0001$ with Mann-Whitney test) and a median whole lung maximal standardized uptake value (wISUVmax) of 4.4 (3.05 to 5.2) in the SSc-ILD group compared to 0.7 ( 0.65 to 0.7 ) in the control group ( $p<0.0001$ ). wIFAPI-MAV and wITL-FAPI were not measurable in control subjects, as no 68Ga-FAPI-04 uptake above background level was observed. In the SSc-ILD group the median wIFAPI-MAV was $254 \mathrm{~cm}^{3}$ (163.4 to 442.3 ) and the median wITL-FAPI was $183.6 \mathrm{~cm}^{3}$ (98.04 to 960.7). ${ }^{68} \mathrm{Ga}$-FAPI-04 uptake was higher in patients with extensive disease, with previous ILD progression or high EUSTAR activity scores. Increased ${ }^{68} \mathrm{Ga}-\mathrm{FAPI}-04$ uptake at baseline was associated with progression of ILD independently of extent of involvement on HRCT scan and the forced vital capacity at baseline. In consecutive ${ }^{68} \mathrm{Ga}$-FAPI-04-PET/CTs, changes in ${ }^{68} \mathrm{Ga}$-FAPI-04 uptake was concordant with the observed response to the fibroblast-targeting antifibrotic agent nintedanib.

Conclusion: Our study presents first in human evidence that ${ }^{68} \mathrm{Ga}-\mathrm{FAPI}-04-\mathrm{fi}-$ broblast uptake correlates with fibrotic activity and disease progression in the lungs of SSc-ILD patients and that ${ }^{68} \mathrm{Ga}-\mathrm{FAPI}-04-\mathrm{PET} / \mathrm{CT}$ may be of potential to improve risk assessment of SSc-ILD.

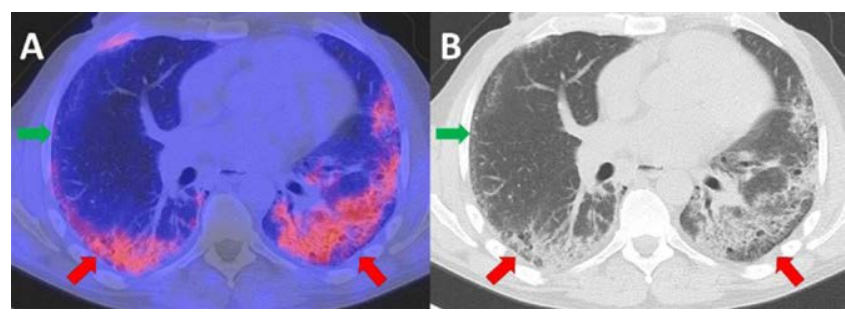

Figure 1. A and B: ${ }^{68} \mathrm{Ga}-\mathrm{FAPI}-04 \mathrm{PET} / \mathrm{CT}$ scan from a patient with SSc-ILD with selective ${ }^{68} \mathrm{Ga}-\mathrm{FAPI}-04$ uptake in fibrotic areas of the left- and right lower lung lobes (red arrows), but not in non-fibrotic areas such as the middle lobe (green arrow). B Corresponding CT component. 
Acknowledgements: We gratefully acknowledge Prof. Uwe Haberkorn (University Hospital Heidelberg and DKFZ, Heidelberg, Germany) and iTheranostics Inc. (Dulles, VA, USA) for providing the precursor FAPI-04.

Disclosure of Interests: Christina Bergmann: None declared, Jörg H.W. Distler Speakers bureau: Actelion, Anamar, ARXX, Pharma, Boehringer Ingelheim, Celgene, Galapagos, GSK, Inventiva, JB Therapeutics, and UCB, Grant/research support from: Anamar, Active Biotech, Array Biopharma, ARXX, aTyr, BMS, Bayer Pharma, Boehringer Ingelheim, Celgene, Galapagos, GSK, Inventiva, Novartis, Sanofi-Aventis, RedX, UCB, Christoph Treutlein: None declared, Koray Tascilar Speakers bureau: Gilead sciences GmbH, Pfizer Turkey, UCB Turkey, Anna-Theresa Mueller: None declared, Armin Atzinger: None declared, Alexandru-Emil Matei: None declared, Johannes Knitza: None declared, Andrea-Hermina Györfi: None declared, Anja Lueck: None declared, Clara Dees: None declared, Alina Soare: None declared, Andreas Ramming: None declared, Verena Schönau: None declared, Oliver Distler Speakers bureau: Arxx Therapeutics, Baecon Discovery, Blade Therapeutics,Bayer, Böhringer Ingelheim, Catenion,Competitive Drug Development International Ltd, Corbuspharma, CSL Behring, ChemomAb, Horizon Pharmaceuticals, Ergonex, Galaapagos NV, Glenmark Pharmaceuticals,GSK, Inventiva, Italfarmaco, IQvia, Kymera, Lilly, Medac, Medscape, MSD, Novartis, Pfizer, Roche, Sanofi, Taget Bio Sciencec, UCB, Grant/research support from: Bayer,Böhringer Ingelheim, Mitsubishi Tanabe Pharma, Olaf Prante: None declared, Philipp Ritt: None declared, Theresa Ida Goetz: None declared, Markus Koehner: None declared, Michael Cordes: None declared, Tobias Baeuerle: None declared, Torsten Kuwert Speakers bureau: Honoraria for occasional lectures by Siemens Healthineers, Grant/research support from: Research grant to the Clinic of Nuclear Medicine by this entity covering projects in the field of SPECT/CT, Georg Schett: None declared, Christian Schmidkonz: None declared DOI: 10.1136/annrheumdis-2021-eular.114

\section{OP0273 \\ THE SCLERODERMA CLINICAL TRIALS CONSORTIUM DAMAGE INDEX (SCTC-DI) IN A SYSTEMIC SCLEROSIS COHORT WITH 10-YEARS FOLLOW-UP}

M. G. Lazzaroni ${ }^{1}$, M. Breda ${ }^{1}$, F. Franceschini ${ }^{1}$, P. Airò ${ }^{1} .{ }^{1}$ ASST Spedali Civili of Brescia, University of Brescia, Rheumatology and Clinical Immunology Unit, Department of Clinical and Experimental Sciences, Brescia, Italy

Background: Systemic Sclerosis (SSc) is characterized by increased mortality and organ damage accrual. A composite SSc Damage Index was recently developed by the Scleroderma Clinical Trials Consortium (SCTC-DI) and was demonstrated as a predictor of mortality both in the Australian derivation cohort and in the Canadian validation cohort.

Objectives: To evaluate in a single centre cohort of SSc patients with 10-years follow-up: (1) the evolution of organ damage over time; (2) factors associated with the development and accrual of organ damage.

Methods: A retrospective analysis was performed on patients prospectively followed in our centre from 1989 to 2019. Organ damage was evaluated with SCTC-DI (0-55 scale; moderate damage $>5$, severe damage $>12$ ) and comorbidities with Charlson Comorbidity Index $(\mathrm{CCl}$, which includes the age of the patient). Patients were included when a follow-up of at least 10 years was available together with SCTC-DI at the diagnosis (baseline, T0), 1 year (T1), 5 years (T5) and 10 years (T10) after the diagnosis. Univariable and multivariable analysis (logistic regression) were performed when appropriated.

Results: 253 SSc patients were included (female 93\%; Caucasians: 99\%; median age at diagnosis: 52 years (IQR: 43-60); diffuse cutaneous subset: 15\%; anti-centromere (ACA) + 55\%; anti-Topoisomerase 1+20\%; anti-RNA polymerase III+: $4 \%$; ever smokers: $28 \%$ ). Median interval between the first SSc symptom other than Raynaud's phenomenon and the diagnosis was 1 year. SCTC-DI progressively increased from diagnosis to T10 ( $p<0.0001$; Kruskal-Wallis test). Moderate damage (score:6-12) was observed in 22 patients at T0 (8.7\%), in 30 at T1 $(11.9 \%)$, in 45 at T5 $(17.7 \%)$ and in 73 at T10 (28.9\%). None of the patients had severe damage (score:13-55) at T0 and T1, while it was present in 6 at T5 (2.4\%) and in 13 at T10 (5.1\%).

At TO no difference in SCTC-DI scores was observed when comparing different subgroups according to gender (female vs. male), disease subsets (diffuse vs. limited) and autoantibodies (ACA- vs. ACA+). At T1, SCTC-DI score was higher in patients with diffuse vs. limited cutaneous subset, and ACA- vs ACA $+(p<0.0001$ for both).

Multivariable analysis demonstrated that a moderate or severe organ damage (SCTC-DI score $>5$ ) at 5 years was positively associated with diffuse cutaneous involvement (p:0.009, OR 4.55, 1.46-14.1), SCTC-DI at TO (p:0.015, OR 1.34, 1.06-1.70) and at T1 (p:<0.0001, OR 1.65, 1.30-2.07), and negatively associated with ACA+ (p:0.024, OR 0.32, 0.12-0.86), while CCl and male sex showed no association. At 10 years SCTC-DI $>5$ was associated with diffuse cutaneous involvement (p:0.013, OR 4.30, 1.36-13.7), SCTC-DI at T5 (p:<0.0001, OR 1.67, 1.38-2.01), while SCTC-DI at TO, CCI, male sex and ACA+ had no association. Among 253 patients, 90 (36\%) died after $>10$ years of follow-up. In non-survivors, as compared to survivors, SCTC-DI score was significantly higher at the baseline (T0) and during the entire follow-up ( $p<0.0001$ for every timepoint).
Conclusion: At the end of 10-years follow-up (T10), 35\% of patients in our cohort had moderate or severe organ damage (SCTC-DI score $>5$ ). Diffuse cutaneous involvement was associated with higher SCTC-DI scores at different time points (T5 and T10). Organ damage, quantified by SCTC-DI at different time points, was confirmed as a factor associated with mortality in patients who reached more than 10 years of follow-up.

REFERENCES:

[1] Ferdowsi N, et al. Ann Rheum Dis. 2019;78:807-16.

Disclosure of Interests: None declared

DOI: 10.1136/annrheumdis-2021-eular.582

\section{PARE Abstract session}

\section{OP0274-PARE EVALUATION OF PATIENT SATISFACTION FOR TELEHEALTH (PHONE AND VIDEO) IN RHEUMATOLOGY OUTPATIENTS DURING COVID-19 PANDEMIC}

Y. Oh ${ }^{1,2}$, A. Hennessey ${ }^{1,2}$, L. Young ${ }^{1,2}$, D. Yates ${ }^{1,2}$, C. Barrett ${ }^{1,2} .{ }^{1}$ Redcliffe Hospital, Rheumatology, Redcliffe, Australia; ${ }^{2}$ The University of Queensland, Medicine, Saint Lucia, Australia

Background: Telehealth via phone (TPhone) or video conference (TVideo) in rheumatology has been a topic of interest for many years. Its use was rapidly expanded due to the international public health emergency of coronavirus dis ease-19 (COVID-19) outbreak in 2020. Australian Medicare Benefits Schedule (MBS) swiftly enabled temporary MBS telehealth items on 13 March 2020, currently extended until 31 March $2021^{1}$. In the early phase of the COVID-19 pandemic, Antony et al. conducted a single-centre public survey to assess patient perception of rheumatology telehealth. Their results showed that $98.4 \%$ of patients consider telehealth acceptable during the pandemic ${ }^{2}$. It is unclear, however, whether this positive perception persists after patients experience a telehealth. In addition, a survey data in 2019 suggested more than half of Australian rheumatologists work in private practice ${ }^{3}$. Therefore, inclusion of private patients will better represent patient perception of telehealth.

Objectives: The aim of this study was to evaluate patient satisfaction with telehealth during the COVID-19 pandemic. This would determine its feasibility to be integrated in future rheumatology outpatient model.

Methods: A questionnaire containing 30 questions was sent to rheumatology patients who attended telehealth appointments at a level 2 public hospital and a local private clinic between April and May 2020. The questionnaires aimed to obtain information on baseline demographics (sex, age, public or private patient, employment status, visual or auditory impairment), appointment details (TPhone or TVideo, usual arrangement for face-to-face (F2F) appointment, cost effectiveness) and appointment satisfaction using a 5-point Likert scale. Descriptive statistical analysis was conducted.

Results: The questionnaire was sent to 1452 patients, of which 494 patients responded (34\%). Female predominance $(77.1 \%)$ and a higher proportion of TPhone $(79.1 \%)$ was seen in the respondents. A majority of patients were existing patients known to the services $(90.9 \%)$. More than $70 \%$ of responses indicated overall satisfaction in specialist care via telehealth, and $88.7 \%$ perceived this suitable during a pandemic. Of all respondents, $21.7 \%$ were prescribed new medication, and the majority of these patients were confident in taking the new medication after the telehealth appointment. Future acceptability for TPhone was significantly lower in private patients compared to public patients $(p=0.01)$. Subgroup analysis revealed that higher telehealth satisfaction was associated with needing to take time off work to attend face-to-face appointment $(p=0.02)$, perception of cost effectiveness $(p<0.001)$ and TVideo $(p=0.03)$.

Conclusion: This is the first study which included both public and private rheumatology patients to evaluate patient satisfaction for telehealth during the COVID-19 pandemic. Overall high level of satisfaction was seen in telehealth most notably associated with its cost effectiveness. A higher percentage of patients who had TVideo compared to TPhone were receptive to future telehealth via TVideo, supportive of the importance of visual cues. This in turn will have significant administrative and technological burdens to coordinate in comparison to a F2F or TPhone review. This qualitative study provides valuable insight of patient perception of telehealth, which has the potential to compliment the traditional rheumatology outpatient model of care following the pandemic.

REFERENCES:

[1] COVID-19 Temporary MBS Telehealth Services 2020 [Available from: http://www.mbsonline.gov.au/internet/mbsonline/publishing.nsf/Content/ Factsheet-TempBB

[2] Antony A, Connelly K, De Silva T, Eades L, Tillett W, Ayoub S, et al. Perspec tives of Patients With Rheumatic Diseases in the Early Phase of COVID-19. Arthritis Care \& Research. 2020;72(9):1189-95.

[3] Association AR. Workforce Survey Exective Summary 20192019 [Available from: https://rheumatology.org.au/members/documents/WorkforceSurveyExecutiveSummary-websiteMay2019.pdf. 